\title{
Solid-state Crystal Growth and Its Application to Fabricate Planar Waveguides
}

\author{
GAN Qi-Jun ${ }^{1,2}$, JIANG Ben-Xue ${ }^{1}$, ZHANG Pan-De ${ }^{1,2}$, JIANG Yi-Guang ${ }^{1,2}$, YANG Chao ${ }^{3}$, \\ ZHANG Wen-Chao ${ }^{3}$, LUO Da-Ping ${ }^{3}$, LI Wen-Xue ${ }^{3}$, ZHANG Long ${ }^{1}$ \\ (1. Key Laboratory of Materials for High Power Laser, Shanghai Institute of Optics and Fine Mechanics, Chinese Academy of \\ Sciences, Shanghai 201800, China; 2. University of Chinese Academy of Sciences, Beijing 100049, China; 3. State Key labo- \\ ratory of Precision Spectroscopy, East China Normal University, Shanghai 200062, China)
}

\begin{abstract}
The effect of different factors, i.e., annealing temperature, grain size, and dopant ion on the solid-state crystal growth (SSCG), was studied in this work. In the SSCG process induced by heat treatment, a single crystal absorbs grains near the bonding interface, forming a robust bond. Using this method, a planar waveguide (PWG) consisting of a core layer of $12 \mathrm{at} \% \mathrm{Yb}$ :YAG polycrystal $(100 \mu \mathrm{m})$ was fabricated and cladded by two YAG single crystal

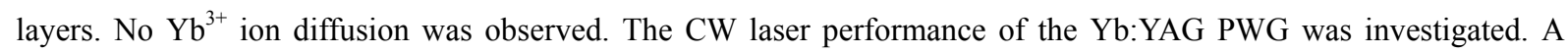
maximum power of $1.14 \mathrm{~W}$ with a slope efficiency of $16.09 \%$ was obtained in the plano-plano resonator, and a maximum power of $1.83 \mathrm{~W}$ with a slope efficiency of $9.59 \%$ was obtained in the three-mirror resonator. A tunable laser with a continuous output between $1027.5 \mathrm{~nm}$ and $1033.5 \mathrm{~nm}$ was realized.
\end{abstract}

Key words: solid-state crystal growth; planar waveguide; laser materials

Solid-state lasers have been playing a critical role in various fields, especially for the high power and high energy lasers in advanced manufacturing industry and laser weapons $^{[1-5]}$. A higher power, better beam quality, higher efficiency, better thermal management, and a more compact structure are the key challenges of this realm. Traditional lasers have reached their limits, and have failed to meet these requirements. Therefore, it is imperative to optimize the structural design of the laser gain media.

A planar waveguide (PWG), composed of a core layer (50-200 $\mu \mathrm{m}$ in thickness) acting as the gain medium and two cladding layers confining the pump-light, provides a new solution to solid-state lasers. Confinement of the pump-light guarantees higher absorption rate and the large aspect ratio of the planar waveguide $(>100)$ ensures a better thermal management ${ }^{[6-9]}$. Some excellent planar waveguide lasers had been reported ${ }^{[10-16]}$. However, the conventional fabrication process of PWG relies on thermal bonding to bind different layers of single crystals or polycrystals $^{[17]}$. Besides, the original bonding interface remains the weakest part of a PWG, especially under high pump powers. Divergence of the coefficient of thermal expansion between the layers can lead to cracks in the bonding interface, which is detrimental to the PWG. Ge et al have reported the fabrication of Nd:YAG PWG using tape casting, which enhances the bonding between the layers ${ }^{[18]}$. Yet, $\mathrm{Nd}^{3+}$ ion diffusion was observed in the PWG, leading to a non-uniform core layer.

Here, we propose an alternative method to fabricate PWG, using the solid-state crystal growth (SSCG). SSCG was used to obtain abnormal grain growth in polycrystals through single crystal seed mediation. Specifically, the polycrystal and the single crystal seed were optically bonded and the single crystal seed was induced to absorb grains near the bonding interface by annealing the pair under appropriate conditions ${ }^{[19-20]}$. In this work, the effect of different factors such as annealing temperature, grain size, and dopant ions on SSCG is reported. Yb:YAG PWG with $\mathrm{Yb}$ :YAG polycrystal as the core layer cladded by two YAG single crystal layers were fabricated successfully.

\section{Experimental Procedure}

A bilayer structure was fabricated to investigate the SSCG process. The fabrication of the bilayer structure (YAG/YAG, YAG/Yb:YAG) and Yb:YAG planar waveguide is schematically illustrated in Fig. 1.

$\mathrm{Yb}$ :YAG polycrystal was prepared by the conventional solid-state reactive sintering. Commercially available high-purity powders of $\alpha-\mathrm{Al}_{2} \mathrm{O}_{3}(99.95 \%), \mathrm{Y}_{2} \mathrm{O}_{3}(99.999 \%)$, and $\mathrm{Yb}_{2} \mathrm{O}_{3}$ (99.99\%) from Alfa Aesar, USA were used as the raw materials and blended at the stoichiometric ratio 
of $\mathrm{Yb}_{0.36} \mathrm{Y}_{2.64} \mathrm{Al}_{5} \mathrm{O}_{12}(12 \mathrm{at} \% \mathrm{Yb}$ :YAG). Ethyl alcohol was used as the solvent and magnesium oxide ( $\mathrm{MgO}, 99.9 \%$, Aladdin, USA) was used as the sintering aid. The powder mixture was ball milled for $12 \mathrm{~h}$ and pre-sintered at $800^{\circ} \mathrm{C}$ for $2 \mathrm{~h}$, and then uniaxially pressed at $5 \mathrm{MPa}$ for $1 \mathrm{~min}$. Subsequently, cold isostatic pressing (CIP) at $200 \mathrm{MPa}$ for $2 \mathrm{~min}$ and vacuum sintering $\left(1760-1780^{\circ} \mathrm{C}\right.$ for $10-30 \mathrm{~h}$ ) were conducted to obtain transparent polycrystals with different grain sizes. YAG polycrystals were synthesized in a similar fashion. On the other hand, YAG single crystals were prepared by the Czochralski $(\mathrm{Cz})$ method.

Furthermore, a piece of the Yb:YAG polycrystal and a piece of YAG single crystal were optically bonded and annealed between $1770-1790^{\circ} \mathrm{C}$ to obtain a bilayer structure. Then, the $\mathrm{Yb}$ :YAG polycrystal layer was polished to $100 \mu \mathrm{m}$ in thickness and another YAG single crystal was optically bonded to its polished face. Finally, it was annealed again to obtain a YAG/Yb:YAG/YAG trilayered PWG. In addition, bilayer structures of (i) YAG single crystal/YAG polycrystal and (ii) YAG single crystal/ Yb:YAG single crystal were prepared.

The interface between the polycrystal and the single crystal was observed by an optical microscope (Olympus BX51) and a scanning electron microscope (SEM, Auriga S40, Zeiss, Germany). A field emission scanning electron microscope (FESEM, 400, Magellan) was used to obtain electron backscattered diffraction (EBSD) image to ascertain the crystal orientation. Besides, inductively coupled plasma mass spectrometry (ICP-MS, X Series II, Thermal Fisher, USA) was used to investigate the $\mathrm{Yb}^{3+}$ ion distribution in the YAG/Yb:YAG/YAG PWG. Finally, the laser performance of the prepared PWG was investigated in both plano-plano resonator and threemirror resonator. The output laser spectrum was meas- ured by a fiber optical spectrum analyzer (Ocean Optics, HR4000) with a resolution of $0.2 \mathrm{~nm}$.

\section{Results and discussion}

Bilayered samples were annealed at $1770^{\circ} \mathrm{C}$ to $1790^{\circ} \mathrm{C}$ for $30 \mathrm{~h}$ in $6 \times 10^{-4} \mathrm{~Pa}$. Figure 2(a) shows the interface of the bilayer structure, i.e., the YAG seed crystal and $\mathrm{Yb}$ :YAG polycrystal, after the thermal treatment $\left(1770^{\circ} \mathrm{C}\right)$. The red dashed line represents the original bonding interface of the bilayered structure. It is apparent that the single crystallization propagated from the seed crystal toward the polycrystalline region over about $20 \mu \mathrm{m}$ distance. Besides, the original interface has disappeared, forming a pore-free bond. The effect of different annealing temperatures was investigated, and the results are displayed in Fig. 2(b) $\left(1780^{\circ} \mathrm{C}\right)$ and Fig. 2(c) $\left(1790^{\circ} \mathrm{C}\right)$. The thicknesses of the grown single-crystal region under the three conditions were $20 \mu \mathrm{m}, 30 \mu \mathrm{m}$, and $40 \mu \mathrm{m}$, respectively. The results indicate that the crystal growth rate increases with the increase of temperature.

The bilayered structure of the YAG single crystal and YAG polycrystal was fabricated following a similar procedure $\left(1780^{\circ} \mathrm{C}, 30 \mathrm{~h}\right)$, to investigate the effect of the dopant ion on SSCG. Figure 3(a) is a montage of the optical micrographs of the sample. In the image, the lighter area implies the single crystal region and the darker area implies the polycrystal region. A maximum thickness of the single crystallization region of $1.16 \mathrm{~mm}$ was achieved, which is much larger than that of the YAG/Yb:YAG precursor $(30 \mu \mathrm{m})$. Besides, the growth rate for $Y A G / Y A G$ was $38.66 \mu \mathrm{m} / \mathrm{h}$, exceeding that reported by Bagayev, et al $(12 \mu \mathrm{m} / \mathrm{h})^{[21]}$.

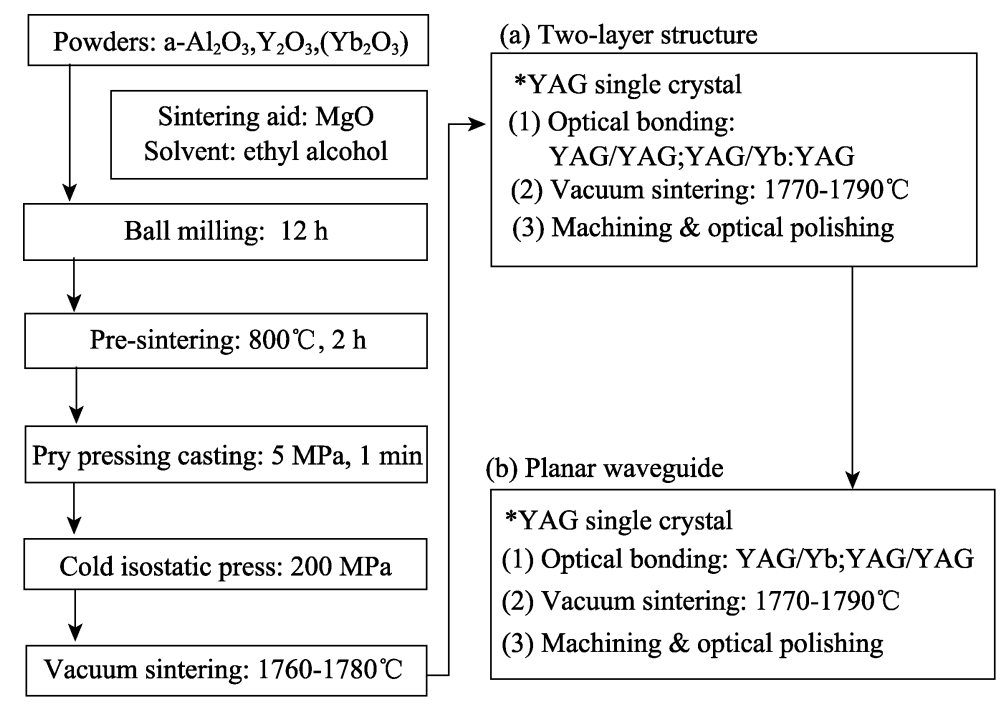

Fig. 1 Schematic of the fabrication of the planar wave guide based on YAG 
Shown in the inset of Fig. 3(a) is the EBSD image of the circled region. Different colors in the image imply different crystal orientations. The largest green area at the top is the newly grown single crystal region with a curved interface and beneath it is the colorful polycrystal region. Figure 3(b) and 3(c) are the SEM and EBSD images of the same region, respectively. The grown single crystal region has the same color as that of the seed crystal (Fig. 3(c)), indicating that the grown crystal has been crystallized into a single crystal. This agrees with that reported by Ikesue, et $a{ }^{[19]}$. A comparison of the growth rates of the YAG/YAG $(38.66 \mu \mathrm{m} / \mathrm{h})$ and YAG/Yb:YAG $(1.33 \mu \mathrm{m} / \mathrm{h})$ bilayered structures under the same annealing condition indicates that it is easier to transform the YAG polycrystal into the single crystal than the $\mathrm{Yb}$ :YAG polycrystal, implying that the doping of $\mathrm{Yb}^{3+}$ ion hinders the SSCG process.

Furthermore, we investigated the effect of the grain size on the SSCG process. Shown in Fig. 4(a) and 4(b) are the SEM images of the interfaces of the samples with polycrystal grain sizes of $40 \mu \mathrm{m}$ and $20 \mu \mathrm{m}$, respectively, which were annealed under the same conditions, exhibiting different single crystal growth thickness of $25 \mu \mathrm{m}$ and $40 \mu \mathrm{m}$, respectively. It is recognized that the single crystal formation by sintering is a process in which the seed single crystal continuously absorbs the fine grains of the polycrystal ${ }^{[19]}$. The smaller the grain is, the easier it is absorbed. Thus, the smaller grains tend to be single-crystallized more easily than the larger ones.

As mentioned above, the planar waveguide structure was achieved via solid-state crystal growth for the first time, and was composed of a core layer $(100 \mu \mathrm{m}$ in thickness) of $\mathrm{Yb}$ :YAG polycrystal and two cladding layers of YAG single crystals. The fabrication process was as follows: transparent $\mathrm{Yb}$ :YAG polycrystal with a grain size

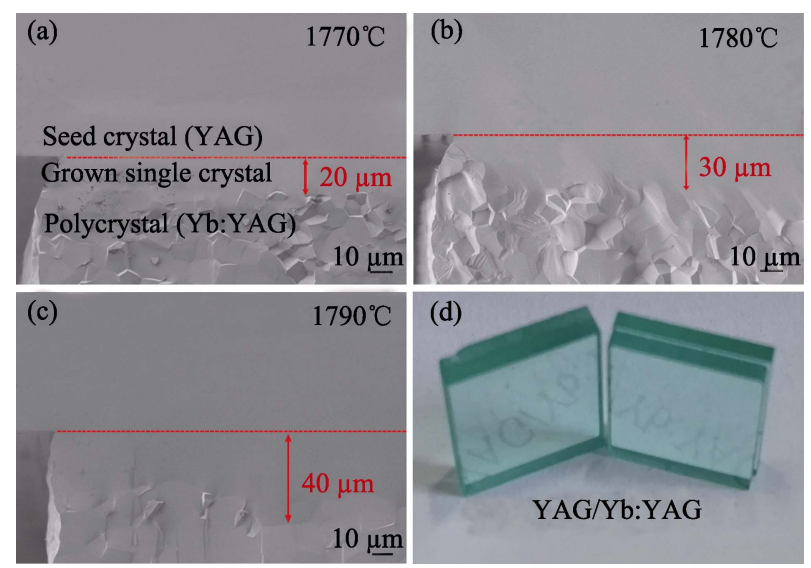

Fig. 2 SEM images of the interfaces after annealing for $30 \mathrm{~h}$ at (a) $1770^{\circ} \mathrm{C}$, (b) $1780^{\circ} \mathrm{C}$ and (c) $1790^{\circ} \mathrm{C}$, (d) photograph of showing the appearance of the YAG/Yb:YAG bilayer structure before annealing

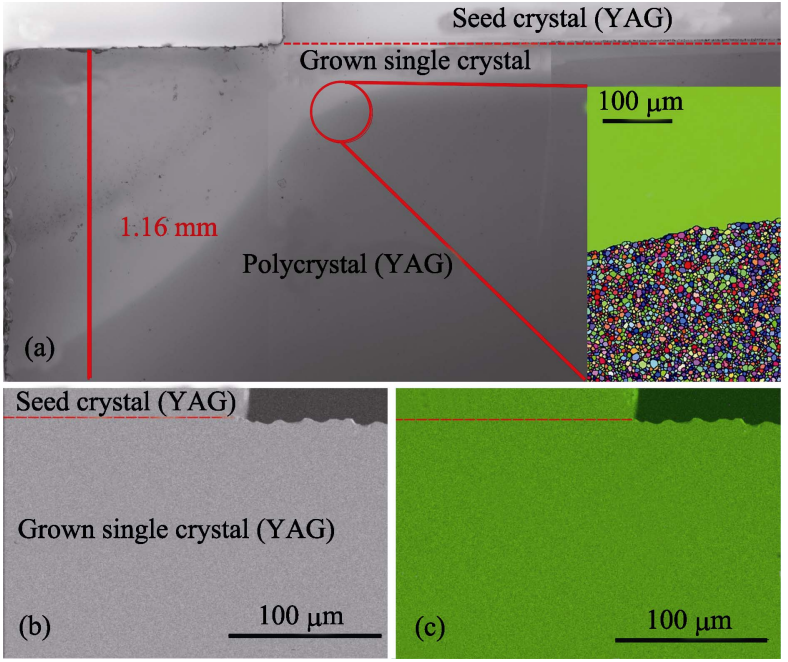

Fig. 3 Morphologies of the interface of the YAG single crystal/YAG polycrystal structure

(a) Optical micrograph (shown in the inset is the EBSD image); (b) SEM image; (c) EBSD image

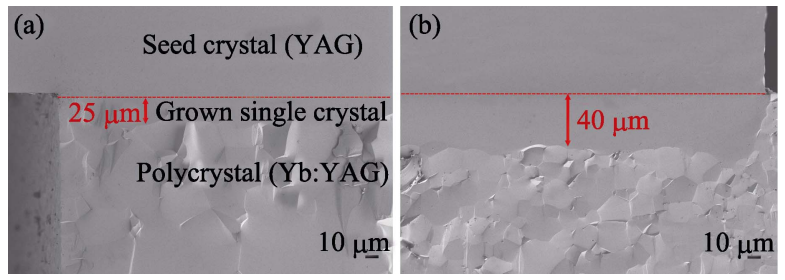

Fig. 4 SEM images of the YAG/Yb:YAG bilayer structure with different grain sizes

(a) $40 \mu \mathrm{m}$; (b) $20 \mu \mathrm{m}$

of $5 \mu \mathrm{m}$ was used as the precursor to obtain the bilayer structure (Yb:YAG polycrystal/YAG single crystal), the optically bonded sample was annealed at $1770^{\circ} \mathrm{C}$ for $15 \mathrm{~h}$, then $\mathrm{Yb}: \mathrm{YAG}$ layer was polished to $100 \mu \mathrm{m}$, after that, another piece of YAG single crystal was optically bonded to the polished face of Yb:YAG polycrystal. At last, the trilayered structure was annealed at $1770^{\circ} \mathrm{C}$ for $15 \mathrm{~h}$ again. Photograph of the sample and SEM images of the upper and lower interfaces are shown in Fig. 5. An ICP-MS line scan was performed from one surface to the other $(1600 \mu \mathrm{m}$ distance $)$ to determine the distribution of the $\mathrm{Yb}^{3+}$ ions across the thickness of the sample. The result (Fig. 6) shows that the distribution of the $\mathrm{Yb}^{3+}$ ions was restricted to the region between $725 \mu \mathrm{m}$ to $825 \mu \mathrm{m}$ from the surface, with a total thickness of $100 \mu \mathrm{m}$, indicating that no $\mathrm{Yb}^{3+}$ ion diffusion had occurred. Besides, the NA of the PWG was estimated to be 0.04 according to the refractive indexes of YAG and $\mathrm{Yb}$ :YAG.

A 12at $\%$ Yb:YAG PWG specimen $(8 \mathrm{~mm} \times 3.5 \mathrm{~mm}$ $\times 3.5 \mathrm{~mm}$ ) synthesized in the same fashion was applied for the $\mathrm{CW}$ laser experiments. Both the plano-plano laser resonator and the three-mirror laser resonator were employed to investigate the spectral characteristics and realize the laser output, as shown in Fig. 7(a) and 7(b), 


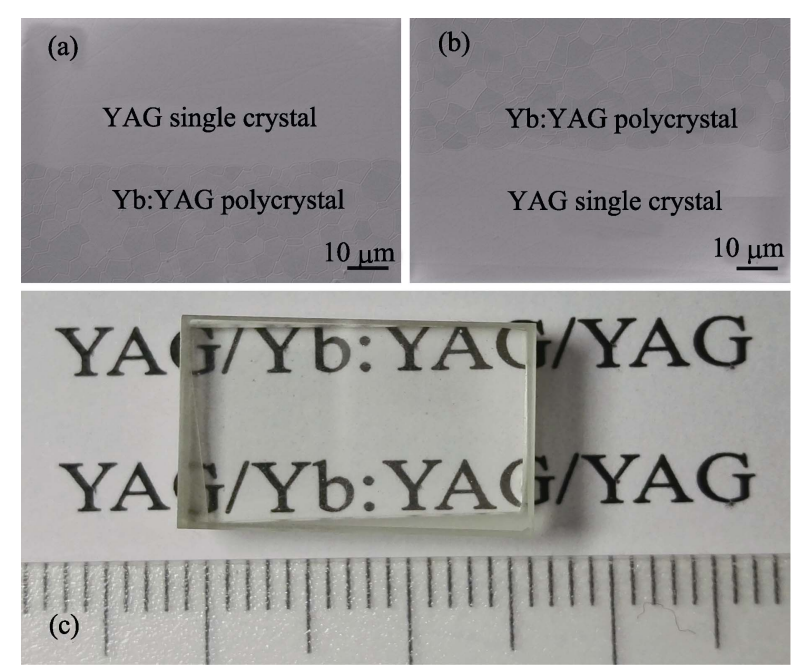

Fig. 5 SEM images of PWG upper interface (a), lower interface (b) and photograph (c) of the Yb:YAG PWG

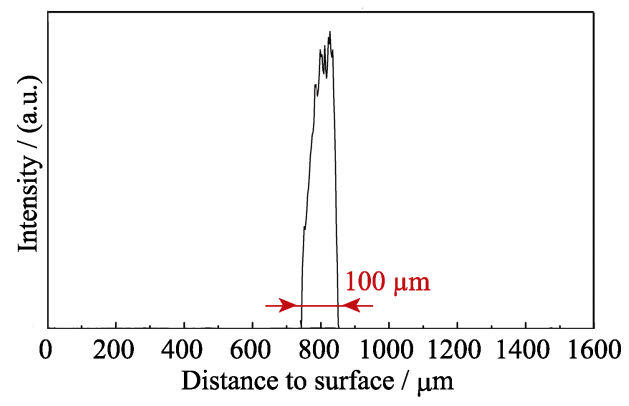

Fig. 6 Concentration distribution of $\mathrm{Yb}^{3+}$ along the thickness of the YAG/Yb:YAG/YAG composite planar waveguide

diode laser with a maximum output power of $30 \mathrm{~W}$ was used as the end-pumping source. The core diameter and numerical aperture (NA) of the fiber coupler were $100 \mu \mathrm{m}$ and 0.22 , respectively. The pump beam was focused onto the core layer of the PWG with a spot diameter of $100 \mu \mathrm{m}$ through the coupling of imaging lenses. The central output wavelength of the pump source was fixed at $974 \mathrm{~nm}$ using diode temperature controlling methods. Both the plano-plano and three-mirror cavities are comprised of a flat dichroic mirror $\mathrm{M}_{1}$ (anti-reflection-coated from 940 to $980 \mathrm{~nm}$, high-reflection-coated from 1000 to $1100 \mathrm{~nm}$ ) at the entrance and an output coupler (OC) with $10 \%$ transmission. Besides, a folding mirror $\mathrm{M}_{2}$ (high-reflection-coated from $1000 \mathrm{~nm}$ to $1100 \mathrm{~nm}$ ) with a curvature of $500 \mathrm{~mm}$ was employed in the three- mirror cavity. The frequency tunability of the specimen was measured by inserting a prism (SF-57) at the Brewster's angle into the three-mirror cavity, as the adjustable element. The Yb:YAG PWG was wrapped with an indium foil and mounted in a water-cooled copper heat sink to efficiently remove the detrimental thermal loads during the experiments. The temperature of the $\mathrm{PWG}$ was maintained at $14^{\circ} \mathrm{C}$. (a)

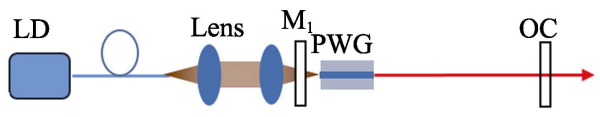

(b)

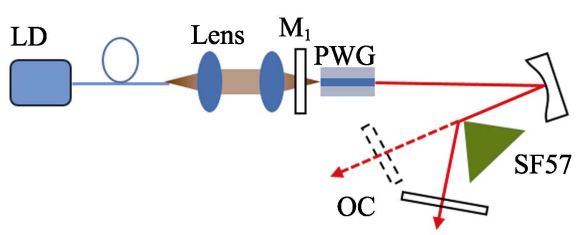

Fig. 7 Experimental setup for the YAG/Yb:YAG/YAG composite planar waveguide $\mathrm{CW}$ laser

(a) Plano-plano resonator; (b) Three-mirror resonator

First, the CW laser operation of the Yb:YAG PWG in the plano-plano laser resonator was investigated. Figure 8(a) shows the laser output power versus the absorbed pump power with the output coupler transmission of $10 \%$, and the laser output was realized when the absorbed pump power was higher than the threshold value of $3 \mathrm{~W}$. A maximum power of $1.14 \mathrm{~W}$ with a slope efficiency of $16.09 \%$ was obtained under an absorbed pump power of $18 \mathrm{~W}$. The output power saturated to a constant value due to PWG gain saturation. The output spectrum was centered at $1030 \mathrm{~nm}$, as shown in Fig. 8(b).

Figure 9 shows the $\mathrm{CW}$ laser performance of the threemirror laser resonator for Yb:YAG PWG. Figure 9(a) shows the average output power versus the absorbed pump power for PWG with an OC of $T=10 \%$. The laser threshold of the absorbed pump power is as low as $3 \mathrm{~W}$. A maximum laser output power of $1.83 \mathrm{~W}$ under the absorbed pump power of $15 \mathrm{~W}$ with a slope efficiency of $9.59 \%$ was obtained with the same output coupler. The laser spectrum in this case was also centered at $1030 \mathrm{~nm}$, as shown in Fig. 9 (b).

The wavelength tunability of the laser was also realized by placing an intracavity prism between $\mathrm{M}_{2}$ and $\mathrm{OC}$ at the Brewster's angle with optimum transmission efficiency. A high dispersion SF57 was used to investigate the wavelength tuning characteristics. The tunable curve of the Yb:YAG PWG was measured at an OC of $T=2 \%$ under $10 \mathrm{~W}$ absorbed pump power, as shown in Fig. 10. The laser spectrum shows a continuous tuning range of $6 \mathrm{~nm}$ between $1027.5 \mathrm{~nm}$ and $1033.5 \mathrm{~nm}$. This indicates that Yb:YAG PWG exhibits a large emission cross-section, and that it can be potentially applied as a modelocked laser.

\section{Conclusion}

Pore-free and fully dense Yb:YAG (12at\%) and YAG polycrystals with different grain sizes were prepared by solid-state reactive sintering and YAG single crystal 

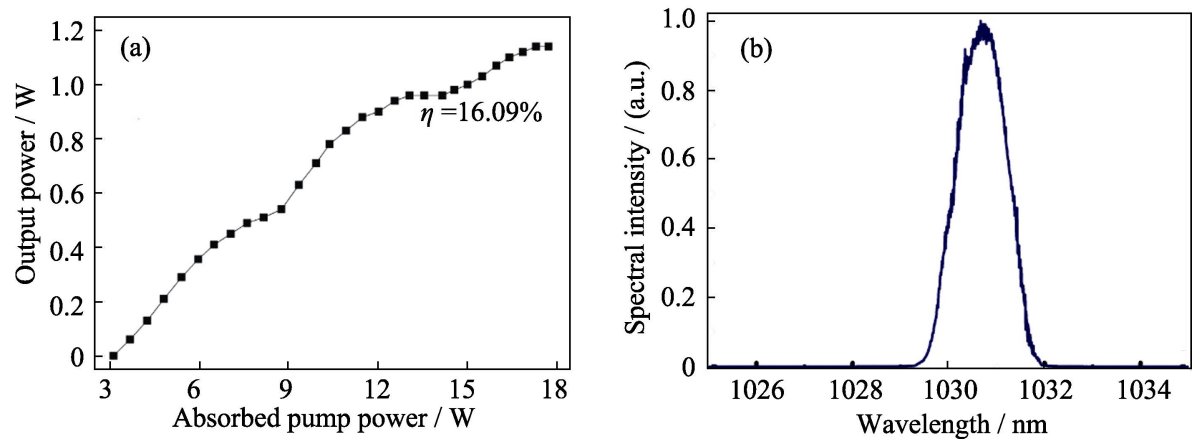

Fig. 8 CW laser performance of a plano-plano resonator for Yb:YAG PWG

(a) Average output power vs the absorbed pump power with $\mathrm{OC}$ of transmission $=10 \%$; (b) Corresponding output spectrum
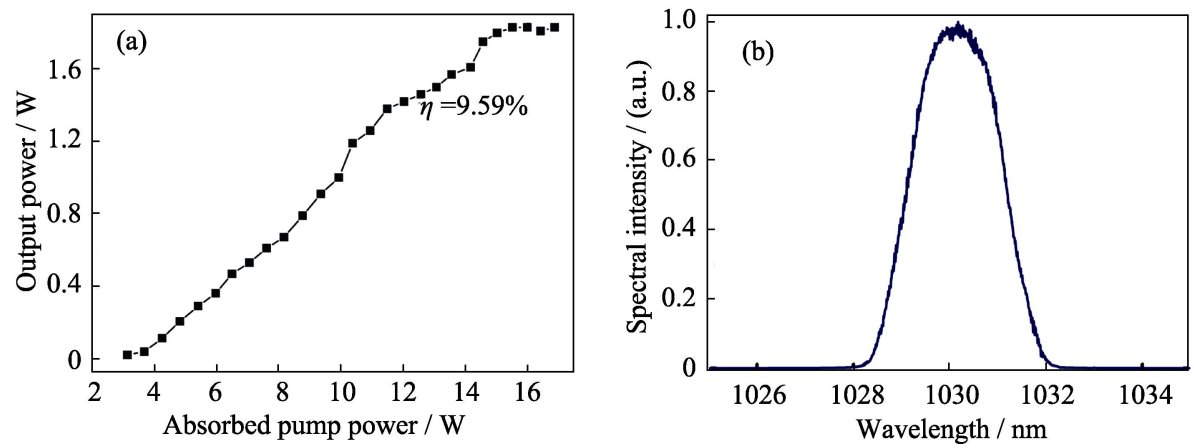

Fig. $9 \mathrm{CW}$ laser performance of the three-mirror resonator for Yb:YAG PWG

(a) Average output power versus the absorbed pump power with an $\mathrm{OC}$ of transmission $=10 \%$; (b) Corresponding output spectrum

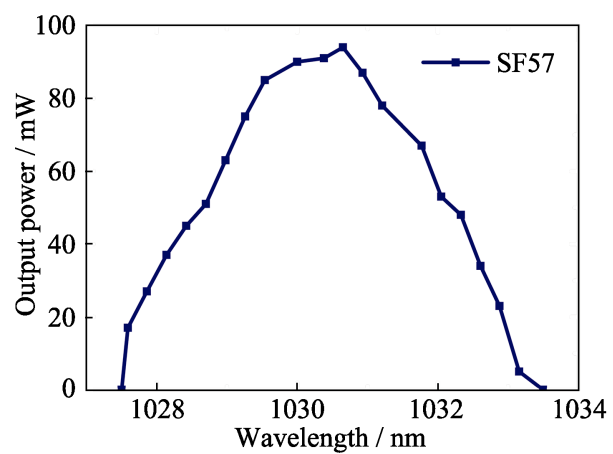

Fig. 10 Tuning curve obtained for a Yb:YAG PWG laser with SF57

seeds were thermally bonded with these samples, respec tively. In the solid-state crystal growth (SSCG) process, the growth rate increases with the increase in the annealing temperature and the decrease of grain size. Growth rates of $1.33 \mu \mathrm{m} / \mathrm{h}$ for $12 \mathrm{at} \% \mathrm{Yb}: \mathrm{YAG}$ polycrystal and $38.66 \mu \mathrm{m} / \mathrm{h}$ for YAG polycrystal were observed. The $\mathrm{Yb}^{3+}$ ion was found to hinder the solid-state crystal growth. A composite-structured planar waveguide with 12at $\% \mathrm{Yb}: Y A G$ polycrystal as the core layer $(100 \mu \mathrm{m})$ cladded by two YAG single crystal layers was successfully fabricated. No $\mathrm{Yb}^{3+}$ ions diffusion was observed as ascertained from the ICP-MS line scan. The CW laser performance of the uncoated Yb:YAG PWG specimen was investigated. Maximum output powers of $1.14 \mathrm{~W}$ (slope efficiency of $16.09 \%$ ) and $1.83 \mathrm{~W}$ (slope efficiency of $9.59 \%$ ) corresponding to plano-plano resonator and three-mirror resonator, respectively, were achieved. A tunable, continuous laser output was realized from 1027.5 to $1033.5 \mathrm{~nm}$ by adding an intracavity dispersion prism. The optical quality and laser performance shall be further improved by a finer design and control of the fabrication procedure and cavity design, to be specific, the ratio of the core layer thickness versus the PWG thickness, the numeric aperture matching between the PWG and input coupler and the design of the resonant cavity.

\section{References}

[1] GIESEN A, SPEISER J. Fifteen years of work on thin-disk lasers: results and scaling laws. IEEE Journal of Selected Topics in Quantum Electronics, 2007, 13(3): 598-609.

[2] KLINGEBIEL S, SCHULTZE M, TEISSET C Y, et al. $220 \mathrm{~mJ}$ Ultrafast Thin-disk Regenerative Amplifier. Proceedings of the CLEO: 2015, San Jose, California, 2015/05/10, 2015. Optical Society of America.

[3] YAMAMOTO B M, BHACHU B S, CUTTER K P, et al. The Use of Large Transparent Ceramics in a High Powered, Diode Pumped Solid-state Laser. Proceedings of the Advanced Solid-State Photonics, Nara, 2008/01/27, 2008. Optical Society of America.

[4] CARROLL D L. Overview of High Energy Lasers: Past, Present, and Future? Proceedings of the 42nd AIAA Plasmadynamics and Lasers Conference, Honolulu, Hawaii, 2011. American Institute of Aeronautics and Astronautics, Inc. 
[5] KALISKY Y, KALISKY O. The status of high-power lasers and their applications in the battlefield. Optical Engineering, 2010, 49(9): 091003-1-4.

[6] SHEPHERD D P, HETTRICK S J, LI C, et al. High-power planar dielectric waveguide lasers. Journal of Physics D-Applied Physics, 2001, 34(16): 2420-2432.

[7] SHEPHERD D P, BONNER C L, BROWN C T A, et al. High-numerical-aperture, contact-bonded, planar waveguides for diode-bar-pumped lasers. Optics Communications, 1999, 160(1/2/3): $47-50$.

[8] MACKENZIE J I. Dielectric solid-state planar waveguide lasers: a review. IEEE Journal of Selected Topics in Quantum Electronics, 2007, 13(3): 626-637.

[9] BEECHER S J, PARSONAGE T L, MACKENZIE J I, et al. Diodeend-pumped 1.2 W Yb: $\mathrm{Y}_{2} \mathrm{O}_{3}$ planar waveguide laser. Optics $E x$ press, 2014, 22(18): 22056-22061.

[10] THOMSON I J, MONJARDIN F J F, BAKER H J, et al. Efficient operation of a $400 \mathrm{~W}$ diode side-pumped Yb:YAG planar waveguide laser. IEEE Journal of Quantum Electronics, 2011, 47(10): 13361345.

[11] MACKENZIE J I. An efficient high-power $946 \mathrm{~nm}$ Nd:YAG planar waveguide laser. Applied Physics B-Lasers and Optics, 2009, 97(2): 297-306.

[12] CALMANO T, PASCHKE A G, M LLER S, et al. Curved Yb:YAG waveguide lasers, fabricated by femtosecond laser inscription. Optics Express, 2013, 21(21): 25501-1-8.
[13] HAKOBYAN S, WITTWER V J, HASSE K, et al. Highly efficient Q-switched Yb:YAG channel waveguide laser with $5.6 \mathrm{~W}$ of average output power. Optics Letters, 2016, 41(20): 4715-4718.

[14] JIA Y, V ZQUEZ DE ALDANA J R, CHEN F. Efficient waveguide lasers in femtosecond laser inscribed double-cladding waveguides of Yb:YAG ceramics. Optical Materials Express, 2013, 3(5): 645-650.

[15] LIU J, GE L, FENG L, et al. Diode-pumped composite ceramic Nd:YAG planar waveguide amplifier with $327 \mathrm{~mJ}$ output at $100 \mathrm{~Hz}$ repetition rate. Chin Opt Lett, 2016, 14(5): 051404.

[16] WU L M, GUO J, XU H L, et al. Ultrasensitive biosensors based on long-range surface plasmon polariton and dielectric waveguide modes. Photonics Res, 2016, 4(6): 262-266.

[17] LEE H C, MEISSNER H E. Characterization of AFB Sapphire Single Crystal Composites for Infrared Window Application. Proceedings of SPIE, 2007. Onyx Optics, Inc.

[18] GE L, LI J, ZHOU Z, et al. Fabrication of composite YAG/Nd:YAG/YAG transparent ceramics for planar waveguide laser. Optical Materials Express, 2014, 4(5): 1042-1049.

[19] IKESUE A, AUNG Y L. Synthesis and performance of advanced ceramic lasers. Journal of the American Ceramic Society, 2006, 89(6): 1936-1944.

[20] IKESUE A, AUNG Y L. Ceramic laser materials. Nat. Photon, 2008, 2(12): 721-727.

[21] BAGAYEV S N, KAMINSKII A A, KOPYLOV Y L, et al. Single crystal growth in YAG ceramics of different stoichiometry. Optical Materials, 2013, 35(4): 757-760.

\title{
固态晶体生长及其在平面波导结构制备上的应用
}

\author{
甘啟俊 ${ }^{1,2}$, 姜本学 ${ }^{1}$, 张攀德 ${ }^{1,2}$, 姜益光 ${ }^{1,2}$, 杨 超 $^{3}$, \\ 张文超 $^{3}$, 罗大平 ${ }^{3}$, 李文雪 ${ }^{3}$, 张 龙 $^{1}$
}

(1. 中国科学院 上海光学精密机械研究所, 强激光材料重点实验室, 上海 201800; 2. 中国科学院大学, 北京 100049; 3. 华东师范大学 精密光谱科学与技术国家重点实验室, 上海 200062)

摘 要: 研究了烧结温度、晶粒大小以及掺杂离子对固态晶体生长的影响。在热致固态晶体生长的过程中, 接近键 合面的陶瓷会被单晶诱导而转变成取向一样的单晶, 同时形成稳固的键合。实验利用这种方法制备核层为 $12 \mathrm{at} \% \mathrm{Yb}: \mathrm{YAG}$ 陶瓷 $(100 \mathrm{~mm})$, 包层为 $\mathrm{YAG}$ 晶体的平面波导结构。这种方法制备的波导结构没有 $\mathrm{Yb}$ 离子的浓度扩 散现象。同时, 还测试了平面波导结构的激光性能: 通过设计平平腔实现了 $1.14 \mathrm{~W}$, 斜率效率 $16.09 \%$ 的激光输出; 在三镜腔中实现 $1.83 \mathrm{~W}$, 斜率效率 $9.59 \%$ 的激光输出。并且激光输出在 $1027.5 \mathrm{~nm}$ 到 $1033.5 \mathrm{~nm}$ 间连续可调。

关 键 词: 固态晶体生长; 平面波导; 激光材料

中图分类号: TQ174 文献标识码: A 